\title{
Mechanism and Malleability of Glucose Dehydration to HMF: Entry Points and Water-
} Induced Diversions

\author{
Meier, Sebastian
}

Published in:

Catalysis Science and Technology

Link to article, DOI:

$10.1039 /$ c9cy02567g

Publication date:

2020

Document Version

Peer reviewed version

Link back to DTU Orbit

Citation (APA):

Meier, S. (2020). Mechanism and Malleability of Glucose Dehydration to HMF: Entry Points and Water-Induced Diversions. Catalysis Science and Technology, 1724-1730. https://doi.org/10.1039/c9cy02567g

\section{General rights}

Copyright and moral rights for the publications made accessible in the public portal are retained by the authors and/or other copyright owners and it is a condition of accessing publications that users recognise and abide by the legal requirements associated with these rights.

- Users may download and print one copy of any publication from the public portal for the purpose of private study or research.

- You may not further distribute the material or use it for any profit-making activity or commercial gain

- You may freely distribute the URL identifying the publication in the public portal

If you believe that this document breaches copyright please contact us providing details, and we will remove access to the work immediately and investigate your claim 


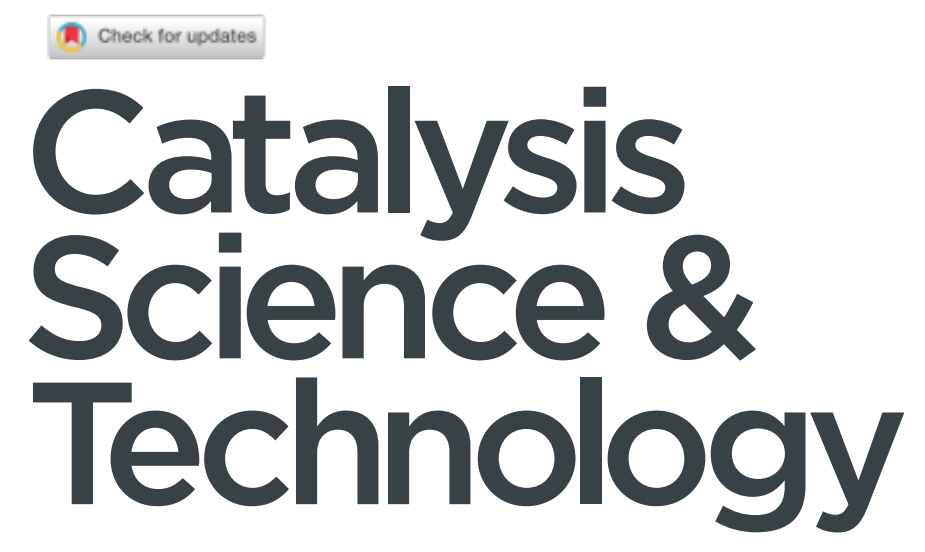

\section{Accepted Manuscript}

This article can be cited before page numbers have been issued, to do this please use: S. Meier, Catal.

Sci. Technol., 2020, DOI: 10.1039/C9CY02567G.
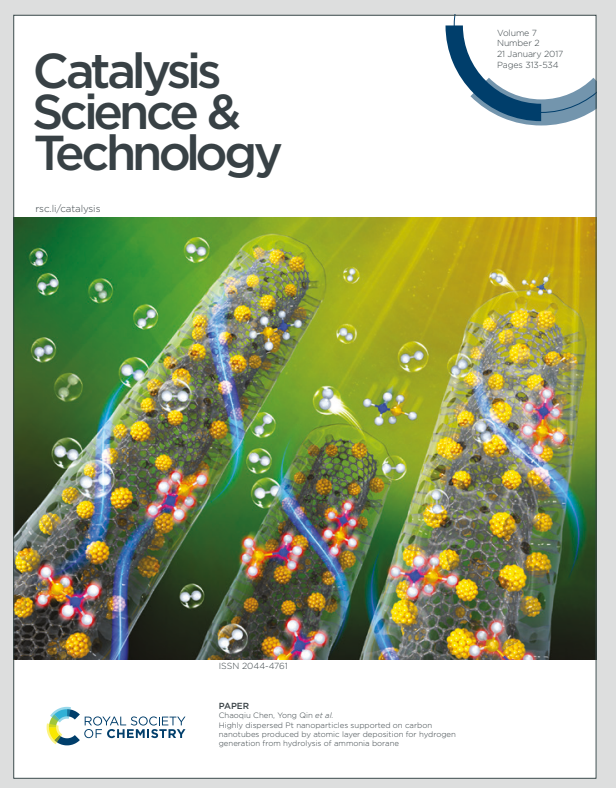

This is an Accepted Manuscript, which has been through the Royal Society of Chemistry peer review process and has been accepted for publication.

Accepted Manuscripts are published online shortly after acceptance, before technical editing, formatting and proof reading. Using this free service, authors can make their results available to the community, in citable form, before we publish the edited article. We will replace this Accepted Manuscript with the edited and formatted Advance Article as soon as it is available.

You can find more information about Accepted Manuscripts in the Information for Authors.

Please note that technical editing may introduce minor changes to the text and/or graphics, which may alter content. The journal's standard Terms \& Conditions and the Ethical guidelines still apply. In no event shall the Royal Society of Chemistry be held responsible for any errors or omissions in this Accepted Manuscript or any consequences arising from the use of any information it contains. 


\title{
ARTICLE
}

\section{Mechanism and Malleability of Glucose Dehydration to HMF: Entry Points and Water-Induced Diversions}

Received 00th January 20xx, Accepted 00th January 20xx DOI: $10.1039 / x 0 x x 00000 x$

\begin{abstract}
Sebastian Meier*a
The stoichiometric dehydration of glucose to 5-hydroxymethylfurfural (HMF) converts an abundant substrate to a versatile chemical. HMF formation can be optimised by using suitable solvents including ionic liquids and DMSO, and by cosolvents such as water. A prerequisite for efficient glucose influx into pathways to HMF is the isomerization of glucose to a ketose, typically the Lewis acid catalysed conversion to fructose. Here, solvent control of the influx of glucose into pathways to HMF is mapped through isotope tracing assays and through kinetic in situ observations. Diversions from the path to HMF in the presence of water are described for the popular $\mathrm{CrCl}_{3} / \mathrm{DMSO}$ system. Addition of water to this system favors the formation of a useful byproduct instead of a mixture of inert compounds. The water-enabled formation of this product is observed for a variety of catalytsts and solvents.
\end{abstract}

\section{Introduction}

The use of biomolecules as sources for fuels and materials has been considered increasingly imminent, not least because of the consequences of anthropogenic $\mathrm{CO}_{2}$ release to the atmosphere. ${ }^{1,2}$ Glucose is the principal product of $\mathrm{CO}_{2}$ reduction in photosynthesis. The pure monomer is accessible upon hydrolysis of its glucose storage forms or structural polymers. Hence, the conversion of glucose to versatile chemicals is a top priority in sustainable chemistry.

Among the most important chemicals that are accessible from glucose is 5-hydroxymethylfurfural (HMF), which is being widely explored as a prospective precursor for polymers, fuel additives, solvents, and pharmaceuticals. ${ }^{3,4}$ The mechanistic pathways from monosaccharides to 5-hydroxymethylfurfural have remained remarkably controversial, as various plausible routes through acyclic or cyclic intermediates can be envisioned. ${ }^{3-8}$ The most efficient approaches to convert glucose to HMF entail the use of suitable Lewis acidic catalysts to convert glucose to fructose prior to dehydration. $2,8-13$ In particular, chromium chloride (as $\mathrm{CrCl}_{2}$ or $\mathrm{CrCl}_{3}$ ) has been established as particularly efficient in converting glucose to HMF. ${ }^{11,14}$

The stoichiometric dehydration of cyclic fructose to HMF is a Brønsted acid catalysed reaction. ${ }^{15,16}$ In aqueous solution, the reaction suffers from poor yields, as HMF is susceptible to rehydration and decomposition to levulinic acid. ${ }^{17}$ However, HMF is a stable product under conditions that disfavor polymerization, for instance when using aprotic polar or ionic

a. Department of Chemistry, Technical University of Denmark, Kemitorvet, Bulding 207, 2800 Kgs Lyngby (Denmark), E-mail: semei@kemi.dtu.dk

tElectronic Supplementary Information (ESI) available: [details of any supplementary information available should be included here]. See DOI: $10.1039 / x 0 x x 00000 x$ liquid solvents and moderate reactant concentrations. The conversion of glucose to HMF in these solvents is limited by the formation of anhydrosugars or disaccharides. ${ }^{18,19}$ These undesired side reactions can be counteracted in the presence of water. Some disagreement persists in the literature, whether the overall selectivity for HMF formation from glucose is improved or impaired by the addition or accumulation of water in the dehydration reaction. ${ }^{3,18}$

Catalysts of interest for the conversion of carbohydrates to value-added chemicals include paramagnetic Lewis acids. At millimolar concentrations, paramagnetic catalysts constitute paramagnetic cosolutes that accelerate the $T_{1}$ relaxation of analyte ${ }^{13} \mathrm{C}$ nuclear spins. ${ }^{19,20}$ Such conditions permit sensitivity improved, quantitative in situ NMR spectroscopy with higher time resolution than experiments in the absence of paramagnetic catalysts could have. Here, this improvement on in situ spectroscopy was employed to gain insight into the entry

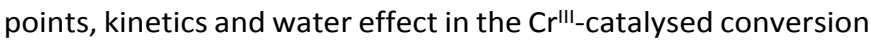
of glucose to HMF in DMSO. Isotope tracking studies show that

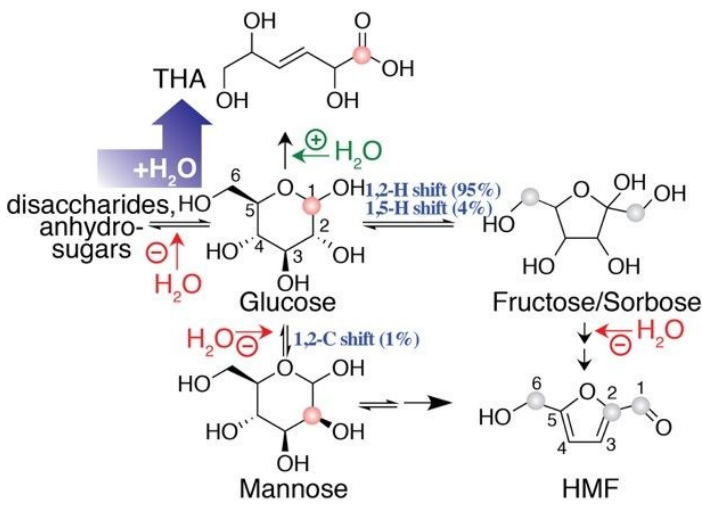

Scheme 1. Schematic overview of the partitioning of glucose into three initia reactions in the conversion to HMF, and of the negative (red) or positive effect of
water on the reactions. 


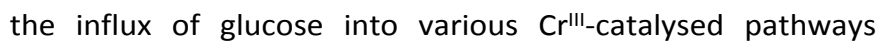
partitions into 1,2 $\mathrm{H}$ shift, 1,5 $\mathrm{H}$ shift and 1,2 $\mathrm{C}$ shift reactions approximately as $95 \%, 4 \%$ and $1 \%$, respectively. This distribution is not significantly affected by the presence of water. Addition of water slows down HMF formation and especially affects the first dehydration reaction of fructose. In addition, glucose is diverted from the HMF pathway to the open chain C6 acid trans-2,5,6-trihydroxy-3-hexenoic acid (THA; Scheme 1) in the presence of water. Selectivity towards THA relative to HMF is found to increase with water content. The yield of HMF is only weakly affected by the presence (or liberation) of water in the stoichiometric dehydration of glucose to $\mathrm{HMF}$ in a DMSO/water solvent system containing predominantly DMSO. A significant benefit of water in such a solvent system is that only one major byproduct with potential use as a polymer building block is formed. Consequences of water addition on HMF formation kinetics have to be considered, as water obstructs the first dehydration step of fructose.

\section{Experimental section}

\section{Chemicals}

$\mathrm{D}_{2} \mathrm{O}\left(99.9\right.$ atom \% D), $d_{6}$-DMSO (99.9 atom \% D), 1,4 dioxane (anhydrous, >99.8\%), $\gamma$-valerolactone (>99\%) D-(+)-glucose $\left(>99.5 \%\right.$, henceforth referred to as glucose), $\left[1-{ }^{13} \mathrm{C}\right] \mathrm{D}$-glucose (99 atom $\%{ }^{13} \mathrm{C}$ ), and $\left[2-{ }^{13} \mathrm{C}\right] \mathrm{D}$-fructose (99 atom $\%{ }^{13} \mathrm{C}$ ) were obtained from Sigma-Aldrich. $\mathrm{CrCl}_{3} \cdot 6 \mathrm{H}_{2} \mathrm{O}(>96 \%), \mathrm{AlCl}_{3} \cdot 6 \mathrm{H}_{2} \mathrm{O}$ (>99\%), and $\mathrm{InCl}_{3}(98 \%)$ were obtained from Merck. For simplicity, $\left[1-{ }^{13} \mathrm{C}\right] \mathrm{D}$-glucose and $\left[2-{ }^{13} \mathrm{C}\right] \mathrm{D}$-fructose will be referred to as $\left[1-{ }^{13} \mathrm{C}\right]$ glucose and $\left[2-{ }^{13} \mathrm{C}\right]$ fructose, henceforth.

\section{Catalytic experiments}

In a typical catalytic experiment, $50 \mathrm{mg}$ monosaccharide and 2$4.5 \mathrm{mg} \mathrm{CrCl}{ }_{3} \cdot 6 \mathrm{H}_{2} \mathrm{O}$ (depending on whether ${ }^{1} \mathrm{H}$ or ${ }^{13} \mathrm{C}$ detected NMR experiments were acquired) were dissolved in $550 \mu \mathrm{l} d_{6^{-}}$ DMSO at room temperature and transferred to a $5 \mathrm{~mm} \mathrm{NMR}$ sample tube. In experiments probing the mechanistic effect of water, a stock solution of $1.2 \mathrm{ml} d_{6}$-DMSO, $150 \mathrm{mg}$ glucose and $7.5 \mathrm{mg} \mathrm{CrCl} \cdot 6 \mathrm{H}_{2} \mathrm{O}$ was prepared. To $400 \mu \mathrm{l}$ of this stock solution, $170 \mu \mathrm{l}$ of $d_{6}$-DMSO, $170 \mu$ l of $\mathrm{D}_{2} \mathrm{O}$ or $85 \mu \mathrm{l}$ each of $\mathrm{D}_{2} \mathrm{O}$ and $d_{6}$-DMSO was added to final fractions of $0 \%, 30 \%$ and $15 \%$ $(\mathrm{v} / \mathrm{v})$ water in DMSO. Sample tubes were transferred to a ceramic spinner turbine and placed into a $600 \mathrm{MHz}$ Bruker NMR spectrometer equipped with a broadband observe (BBFO) SmartProbe equilibrated to the desired temperature (110-130 $\left.{ }^{\circ} \mathrm{C}\right)$.

\section{NMR spectroscopy}

Kinetic in situ experiments were acquired as series of ${ }^{1} \mathrm{H}$ or ${ }^{13} \mathrm{C}$ NMR spectra in a pseudo-2D fashion using a $600 \mathrm{MHz}$ Bruker Avance III NMR spectrometer equipped with a SmartProbe, using $d_{6}$-DMSO as the lock substance in all circumstances. Free induction decays were sampled as 16384 complex data points using a spectral width of $16 \mathrm{ppm}$ during an acquisition time of 1.7 seconds in the case of ${ }^{1} \mathrm{H}$ spectra, while $64 \mathrm{k}$ complex data points (spectral width of $240 \mathrm{ppm}$ ) were sampled frtifor $_{\text {itin } 8}$ seconds (aq) in the case of ${ }^{13} \mathrm{C}$ spectra. Intertscappecyeferefelatys of 2 seconds were used for the series of ${ }^{1} \mathrm{H}$ spectra. Recycle delays of 3 seconds were used for ${ }^{13} \mathrm{C}$ spectra. Automatic shimming by Bruker Topspin Topspin 3.5 pl7 software during the experiment was employed.

${ }^{13} \mathrm{C}_{1}$ relaxation times had previously been measured on $\mathrm{Cr}^{\prime \prime \prime}$ containing reaction mixtures showing that the $\mathrm{Cr}^{\prime \prime \prime}$ had shortened relaxation times to below $1 \mathrm{~s}$ for glucose and $\mathrm{HMF}^{13} \mathrm{C}$ spins. Such shortened relaxation times have the benefit that ${ }^{13} \mathrm{C}$ spectra in reaction tracking were quantitative (sum of recycle delay and acquisition time corresponds to $\sim 5 \cdot T_{1}$ ) with high time resolution and sensitivity. Pseudo-2D spectra were processed in Bruker Topspin 3.5 pl7 with baseline correction and integrated using the Dynamics module of the software. Signal areas rather than intensities of the reactants, intermediates and products were considered.

\section{Data analysis}

Signal areas were fitted using pro Fit 7 (QuantumSoft, Zurich). Data and fits were plotted in pro Fit 7 . For the experiment containing $30 \%(\mathrm{v} / \mathrm{v})$ water in the $\mathrm{CrCl}_{3}$ catalysed reaction in $d_{6^{-}}$ DMSO, rates of product formation were determined as the slopes of product formation against time, while selectivity was determined as the slope of product formation relative to the slope of glucose consumption. Rate and selectivity were plotted against the reaction progress (glucose conversion) in Fig. 7 alongside trend lines to guide the eye.

\section{Results and discussion}

\section{${ }^{13} \mathrm{C}$ Isotope flux analysis of pathways to HMF}

Efficient influx of substrate into pathway intermediates that can be rapidly dehydrated to $\mathrm{HMF}$ is a prerequisite for the efficient conversion of carbohydrates. The entry point for glucose into the $\mathrm{HMF}$ forming pathway catalysed by $\mathrm{CrCl}_{3}$ was established under conditions of HMF formation. The initial reactions of glucose (at sufficiently low concentration to disfavor humin formation) with $\mathrm{CrCl}_{3}$ are not well defined, as 1,2 hydride transfer (H-shift), 1,5 $\mathrm{H}$-shift and 1,2 carbon shift (C-shift) reactions may occur in the presence of $\mathrm{CrCl}_{3}$ catalysis. ${ }^{2}$ The partitioning of glucose influx into the different reactions was assessed by isotope tracking on the product HMF. ${ }^{13} \mathrm{C}$-assisted flux analysis using product labeling from ${ }^{13} \mathrm{C}$ glucose substrate is widely employed in metabolic research, ${ }^{21,22}$ while being considerably less widely established in chemocatalytic investigations. ${ }^{23}$ Both 1,2 and 1,5 $\mathrm{H}$-shift convert glucose to ketoses (fructose and sorbose, respectively), which are onpathway intermediates towards HMF. In contrast, a 1,2 C-shift converts glucose to mannose as an off-pathway intermediate.

Isotopic isomers (isotopomers) of HMF formed from $\left[1-{ }^{13} \mathrm{C}\right]$ were tracked by NMR spectroscopy. HMF was found to be enriched with ${ }^{13} \mathrm{C}$ at the positions 1,6 and 2 respectively, while the three remaining positions contained ${ }^{13} \mathrm{C}$ at natural abundance. $\left[1-{ }^{13} \mathrm{C}\right] \mathrm{HMF},\left[6-{ }^{13} \mathrm{C}\right] \mathrm{HMF}$ and $\left[2-{ }^{13} \mathrm{C}\right] \mathrm{HMF}$ derive from $\left[1{ }^{13} \mathrm{C}\right]$ glucose following $1,2 \mathrm{H}$-shift, $1,5 \mathrm{H}$-shift and 1,2 C- 


$$
\begin{aligned}
& {\left[1-{ }^{13} \mathrm{C}\right] \text { glucose } \stackrel{1,2 \mathrm{H} \text {-shift }}{\longrightarrow}\left[1-{ }^{13} \mathrm{C}\right] \text { fructose } \rightarrow\left[1-{ }^{13} \mathrm{C}\right] \mathrm{HMF} 95 \%} \\
& {\left[1--^{13} \mathrm{C}\right] \text { glucose } \stackrel{\mathrm{H}-\text { shift }}{\longrightarrow}\left[6-{ }^{13} \mathrm{C}\right] \text { sorbose } \rightarrow\left[6-{ }^{13} \mathrm{C}\right] \mathrm{HMF} \quad 4 \%} \\
& {\left[1-{ }^{13} \mathrm{C}\right] \text { glucose } \stackrel{1,2 \mathrm{C} \text {-shift }}{\longrightarrow}\left[2-{ }^{13} \mathrm{C}\right] \text { mannose } \rightarrow\left[2-{ }^{13} \mathrm{C}\right] \mathrm{HMF} \quad 1 \%}
\end{aligned}
$$

Fig. 1. Conversion of $\left[1^{-13} \mathrm{C}\right]$ glucose through different initial reactions. Resultant isotopic isomer distributions are shown after $\mathrm{CrCl}_{3}$ catalysis in DMSO.
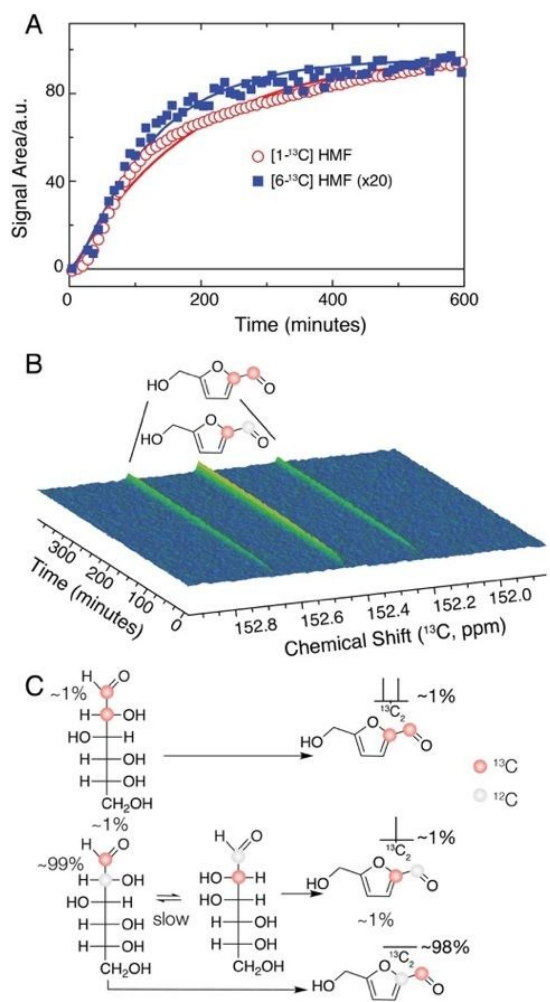

Fig. 2. (A) Reaction progress for the conversion of $\left[1-{ }^{13} \mathrm{C}\right]$ glucose to $\left[1-{ }^{13} \mathrm{C}\right] \mathrm{HMF}$
and $\left[6-{ }^{13} \mathrm{C}\right] \mathrm{HMF}$ (2Ofold scaling) and fits to a model for consecutive first order reactions. (B) Series of ${ }^{13} \mathrm{C}$ spectra showing the formation $\left[2-{ }^{13} \mathrm{C}\right] \mathrm{HMF}$ through 1,2 C-shift, yielding the central signal. (C) Routes to the HMF isotopomers shown in (B) through $1,2 \mathrm{H}$-shift of glucose containing natural abundance $(\sim 1 \%){ }^{13} \mathrm{C} 2$, in addition to enriched ${ }^{13} \mathrm{C} 1$ (top), or through 1,2 C-shift (middle). The vast majority ${ }^{13} \mathrm{C}$ glucose, $2.5 \mathrm{mg} \mathrm{CrCl} .6 \mathrm{H}_{2} \mathrm{O}, 550 \mu \mathrm{ld}$ - DMSO, $110^{\circ} \mathrm{C}$

shift reactions, respectively (Fig. 1). Quantification of the isotopomers indicates that approximately $95 \%$ of glucose reacts through a 1,2 $\mathrm{H}$-shift, while $4 \%$ react though a 1,5 $\mathrm{H}$-shift and only $1 \%$ reacts through a $1,2 \mathrm{C}$-shift under reaction conditions to HMF. Both $\left[6-{ }^{13} \mathrm{C}\right]$ sorbose ${ }^{2,19}$ and $\left[2-{ }^{13} \mathrm{C}\right]$ mannose (Fig. S2) were found in the reaction mixture, thus supporting the conversion of glucose to HMF through the depicted pathways.

Kinetic details in the formation of the different isotopomers were then compared. The kinetics of $\left[6-{ }^{13} \mathrm{C}\right] \mathrm{HMF}$ formation and of $\left[1^{13} \mathrm{C}\right] \mathrm{HMF}$ formation are compared in Fig. 2. The formation of $\left[6-{ }^{13} \mathrm{C}\right] \mathrm{HMF}$ occurs in parallel to the formation of $\left[1-^{13} \mathrm{C}\right] \mathrm{HMF}$, but reaction progress to both isotopomers followed a slightly different progress curve. The formation of $\left[6-{ }^{13} \mathrm{C}\right] \mathrm{HMF}$ was in better agreement with a model of consecutive first order reactions than is the formation of $\left[1-{ }^{13} \mathrm{C}\right] \mathrm{HMF}$, which displays a slower increase of HMF (Fig. 2A). The observation is consistent with recent reports that Lewis acids may coordinate glucose as 1:2 complexes in reactions leading to $1,2 \mathrm{H}$-shifts. ${ }^{10,24,25}$ The sterically different substrate-catalyst complexes in $1,1,5$ it H-shifts appear to be less prone to 1:2 complexation-gulaging from 5 the kinetic progress displayed in Fig. 2.

The kinetics of $\left[2-{ }^{13} \mathrm{C}\right] \mathrm{HMF}$ formation upon an initial $1,2 \mathrm{C}-$ shift is shown in Fig. 2B. The formation of $\left[2-{ }^{13} \mathrm{C}\right] \mathrm{HMF}$ proceeds with a kinetics akin to the competing 1,2 $\mathrm{H}$-shift pathway and at amounts comparable to the natural abundance species producing $\left[1,2-{ }^{13} \mathrm{C}\right] \mathrm{HMF}$. This species is formed from glucose labelled at $\mathrm{C} 1$ and carrying $1 \%$ natural abundance ${ }^{13} \mathrm{C}$ enrichment at the $\mathrm{C} 2$ position via a 1,2 $\mathrm{H}$-shift. Approximately $1 \%$ of $\left[1-{ }^{13} \mathrm{C}\right]$ glucose thus reacts through a $1,2 \mathrm{C}$-shift.

\section{${ }^{13} \mathrm{C}$ Isotope influx into pathways to HMF with different catalyst and substrate}

When repeating the experiment with In $^{\text {III }}$ instead of $\mathrm{Cr}^{\prime \prime \prime}$ catalysis, no enrichment of the $\mathrm{C} 2$ and $\mathrm{C} 5$ positions were found, thus indicating that 1,2 C-shift and 1,5 $\mathrm{H}$-shift are largely disfavored for some Lewis acid catalysis (Fig. 3). This

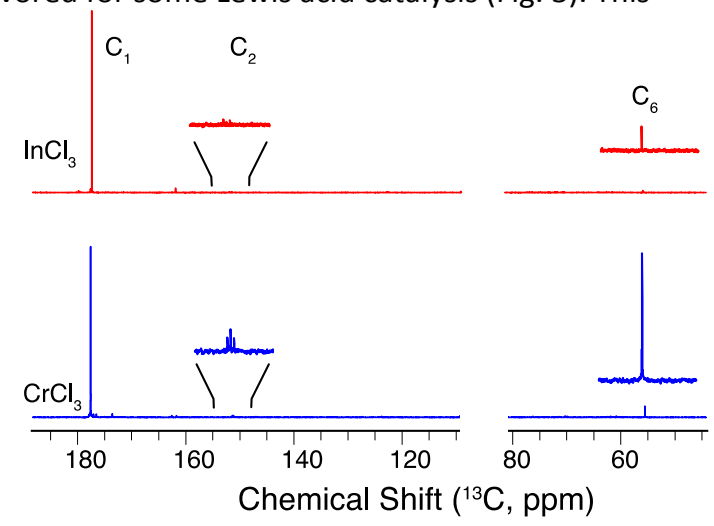

Fig. 3. $\mathrm{HMF}$ isotopomer distributions in ${ }^{13} \mathrm{C}$ NMR spectra upon In ${ }^{\prime \prime \prime}$ and $\mathrm{Cr}$ "II catalysis. In'II catalysis showed lower propensity for 1,5 H-shift and 1,2 C-shift than Cr'll, resulting in reduced singlet signals for $\mathrm{C} 2$ and $\mathrm{C} 6$ in $\mathrm{HMF}^{\prime}$. Reaction conditions:
$50 \mathrm{mg}\left[1-{ }^{13} \mathrm{C}\right]$ glucose, $4.5 \mathrm{mg} \mathrm{CrCl}{ }_{3} \cdot 6 \mathrm{H}_{2} \mathrm{O}$ or $3 \mathrm{mg} \mathrm{InCl}{ }_{3} 550 \mu d_{6}-\mathrm{DMSO}, 130{ }^{\circ} \mathrm{C}$ for 20 hours.

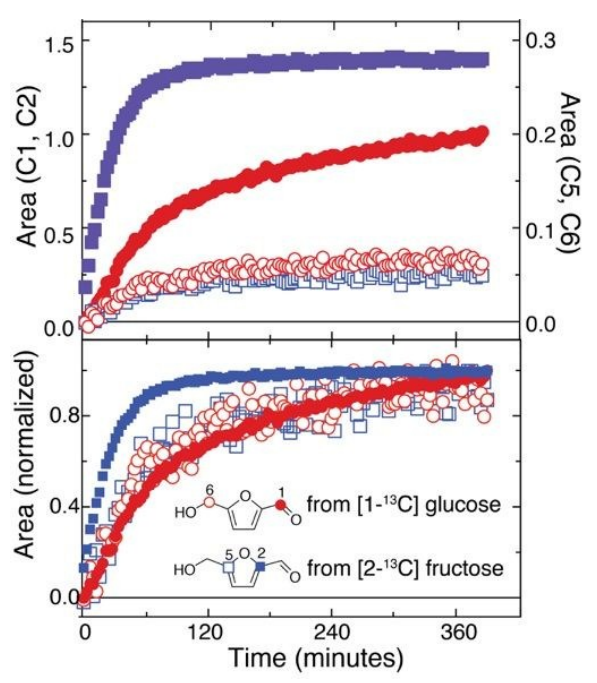
Fig. 4. Reaction progress for the competitive conversion of $[1-13 \mathrm{C}]$ glucose to [1-
$\left.{ }_{13} \mathrm{C}\right] \mathrm{HMF}$ and $\left[6-^{13} \mathrm{C}\right] \mathrm{HMF}$ and of $\left[2-^{13} \mathrm{C}\right]$ fructose to $\left[2-^{13} \mathrm{C}\right] \mathrm{HMF}$ and $\left[5-^{13} \mathrm{C}\right] \mathrm{HMF}$ shows lower fraction of $1,5 \mathrm{H}$-shift in fructose than in glucose (top). Normalised kinetic profiles indicate slower conversion of isotopomers formed through at least one aldose along the pathway ( $\mathrm{C} 1, \mathrm{C} 5, \mathrm{C} 6$ enriched $\mathrm{HMF}$, bottom) as compared to $\left[2-{ }^{13} \mathrm{C}\right] \mathrm{HMF}$ formed from direct fructose dehydration. Reaction conditions: $25 \mathrm{mg}$ $\left[1-{ }^{13} \mathrm{C}\right]$ glucose, $25 \mathrm{mg}\left[2-{ }^{13} \mathrm{C}\right]$ fructose, $3 \mathrm{mg} \mathrm{CrCl} \cdot 6 \mathrm{H}_{2} \mathrm{O}, 550 \mu \mathrm{l} d_{6}-\mathrm{DMSO}, 130{ }^{\circ} \mathrm{C}$. 
observation parallels similar observations for the isomerization reaction of glucose by In"I and Cr'II catalysis in water, which had suggested low propensity of In"I to catalyze 1,2 C-shifts in glucose. ${ }^{2}$

The kinetic experiment of carbohydrate conversion to HMF was repeated using a $1: 1$ substrate mixture of $\left[1-{ }^{13} \mathrm{C}\right]$ glucose and $\left[2-{ }^{13} \mathrm{C}\right]$ fructose. Here, $\left[2-{ }^{13} \mathrm{C}\right] \mathrm{HMF}$ and $\left[5-{ }^{13} \mathrm{C}\right] \mathrm{HMF}$ arise as the main product species from $\left[2-{ }^{13} \mathrm{C}\right]$ fructose with kinetics as shown in Fig. 4. The formation of $\left[2-{ }^{13} \mathrm{C}\right] \mathrm{HMF}$ from fructose is distinctly faster than formation of $\mathrm{HMF}$ from glucose and follows a different kinetic profile. ${ }^{26}$ The fraction of $\left[2-{ }^{13} \mathrm{C}\right]$ fructose reacting to $\left[5-{ }^{13} \mathrm{C}\right] \mathrm{HMF}$ is smaller than the fraction of $\left[1-{ }^{13} \mathrm{C}\right]$ glucose reacting to $\left[6^{-13} \mathrm{C}\right] \mathrm{HMF}$, possibly due to the 1,5 $\mathrm{H}$-shift competing with the faster conversion of fructose to HMF. In addition, the formation of $\left[5-{ }^{13} \mathrm{C}\right] \mathrm{HMF}$ is considerably slower than the formation of $\left[2-{ }^{13} \mathrm{C}\right] \mathrm{HMF}$, as the conversion of fructose to aldoses by a $1,5 \mathrm{H}$ shift introduces additional reaction steps for the formation of HMF via this pathway.

\section{Influence of water on kinetics and selectivities}

The Cr'll catalysed conversion of glucose to HMF has previously been described in water, DMSO and mixtures of the solvents. ${ }^{11,18}$ The isotopic distribution in HMF formed from [1${ }^{13} \mathrm{C}$ ] glucose was thus probed with ${ }^{13} \mathrm{C}$ NMR spectra upon $\mathrm{Cr}^{\text {III }}$ catalysis in DMSO and water. Cr'II catalysis showed approximately twofold lower propensity for 1,2 C-shift in water than in DMSO (Fig. S3). Different binding behavior to the paramagnetic $\mathrm{Cr}^{\text {III }}$ center in response to altered solvent composition can be corroborated by probing the $\mathrm{Cr}^{\text {III-induced }}$ paramagnetic relaxation ${ }^{20}$ of different chemicals at different solvent compositions. These observations indicate changes in binding behavior of oxygen-containing compounds upon altered solvent composition (Fig. S4) and stipulated the enquiry of further solvent-induced changes to the catalytic pathway towards HMF.

Conflicting views have been held on the water effect on the

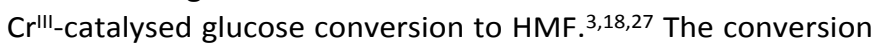
of glucose to HMF is a dehydration process, whose efficient progress has been linked to the water removal methods. ${ }^{28}$ Some recent studies have nevertheless emphasised a neutral or even beneficial effect of $15-50 \%$ water on HMF formation, ${ }^{18}$ as water suppresses the sequestration of glucose into unreactive disaccharides and anhydroglucose forms. ${ }^{18,19}$ The effect of water in the Cr'II-catalysed glucose conversion to HMF was thus scrutinised in more detail using in situ NMR.

Resultant spectra of glucose conversion to $\mathrm{HMF}$ in the absence and in the presence of water are shown in Fig. 5. Excellent signal to noise ratios were rapidly obtainable with ${ }^{13} \mathrm{C}$ NMR spectroscopy due to the rapid relaxation of the nuclei in the presence of $\mathrm{Cr}^{\text {III }}$ catalyst. In the absence of water, fructose and compound 1 ((4R,5R)-4-hydroxy-5-hydroxymethyl-4,5dihydro-furan-2-carbaldehyde intermediate) $)^{29}$ were detected in a time-resolved manner, in addition to the formation of disaccharides and anhydroglucose forms (Fig. S5-S7). Addition of water reduced formation of disaccharides and anhydroglucoses as expected. ${ }^{18}$ Under the used reaction
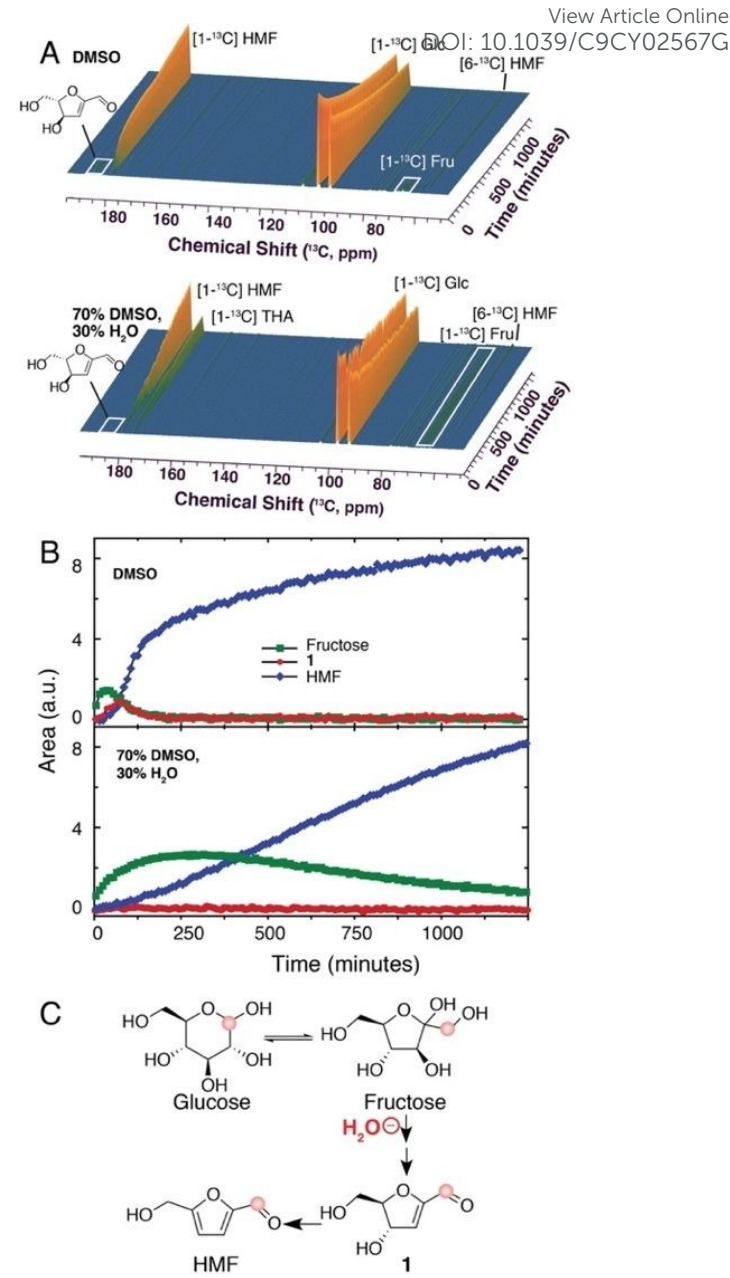

Fig. 5. (A) Series of ${ }^{13} \mathrm{C}$ spectra for the dehydration of $\left[1^{13} \mathrm{C}\right]$ glucose in the presence and in the absence of added water. Spectral regions for relevant intermediates and byproducts are indicated. (B) Signal areas for the intermediate fructose and (4R,5R)-4-hydroxy-5-hydroxymethyl-4,5-dihydrofuran-2-carbaldehyde in the conversion of glucose to $\mathrm{HMF}$ with and without added water (C). Impeded dehydration of fructose leads to slow formation of $\mathrm{HMF}$ in the presence $550 \mu \mathrm{l} d_{6}$-DMSO, $110^{\circ} \mathrm{C}$.

conditions, the hydrothermal reference reaction led to the formation of anhydroglucose forms in the absence of added water, while other reactions only included spurious formation of HMF, which was negligible compared to reactivity in the presence of $\mathrm{Cr}^{\text {III }}$ catalyst (Fig. S8). Additional changes to reaction progress in the presence of water included the accumulation of fructose, while accumulation of compound 1 was reduced in the presence of water (Fig. 5, 6). Glucose conversion rates were minutely affected and conversion proceeded only marginally slower upon addition of up to $30 \%$ water (Fig. 5). Isotope distributions among HMF formed through initial 1,5 H-shift and 1,2 C-shift was not significantly affected by the addition of water. Overall, the addition of water primarily reduced the rate of the first step of fructose dehydration (Fig. 5C). This observation is consistent with the prediction that solvation of substrates with larger numbers of hydroxyl groups leads to higher activation energies and more strongly reduced dehydration rates in the presence of water (for instance slowing the dehydration of fructose as compared to the dehydration of 


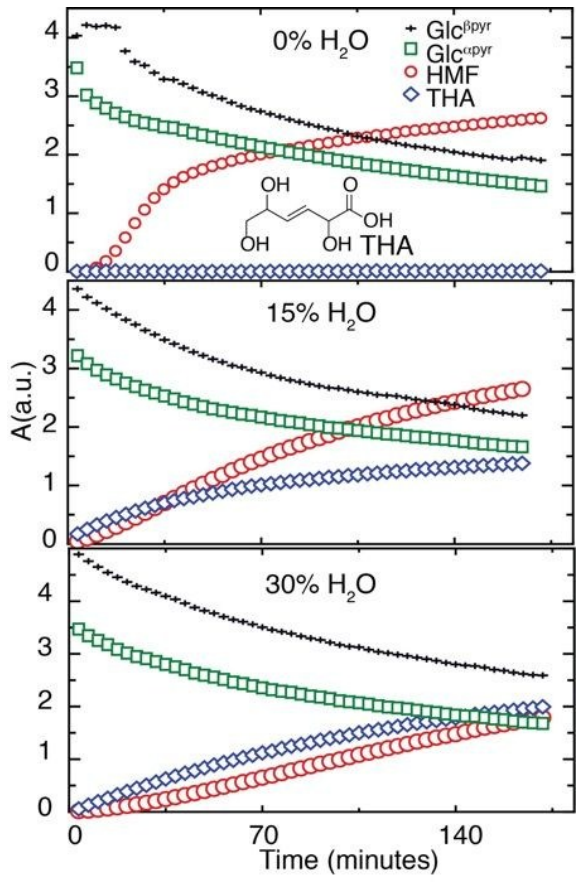

Fig. 6. Signal areas for the equilibration of glucose anomers and their conversion to $\mathrm{HMF}$ and THA in the absence and in the presence of added water, as followed by a series of ${ }^{1} \mathrm{H}$ NMR spectra. Reaction conditions: $50 \mathrm{mg}$ glucose,
$\mathrm{CrCl}_{3} \cdot 6 \mathrm{H}_{2} \mathrm{O}, 570 \mu \mathrm{l} d_{6}$-DMSO or $\mathrm{D}_{2} \mathrm{O}$ at the indicated volume ratio, $130{ }^{\circ} \mathrm{C}$.

1). ${ }^{30,31}$ In contrast, glucose isomerization is less affected, consistent with the negligible effect of water on hydride shifts as observed from isotope distributions in HMF (Fig. S3).

In addition to modulating rates in fructose dehydration to HMF, water elicits a mechanistic change in the $\mathrm{Cr}^{\prime \prime \prime}$-catalysed conversion of glucose. With increasing amounts of water, increasing amounts of a linear product were detected that is not formed in the absence of water. This compound can be identified as trans-2,5-dihydroxy-3-pentenoic acid (THA). THA, which was only recently described in the $\mathrm{Sn}^{\mathrm{IV}}$-catalysed conversion of glucose and fructose, likely forms via an acyclic pathway through the 1,2 dicarbonyl compound 3,4dideoxyglucosone-3-ene. ${ }^{8,32}$ Notably, the kinetics of THA formation follows a distinctly different progress curve than the kinetics of HMF formation. Thus, the formation of HMF shows the distinct sigmoidal reaction progress characteristic of sequential reactions with accumulation of some intermediate (here fructose and 1). In contrast, THA formation does not follow a sigmoidal kinetics, thus indicating that THA can be formed directly from glucose in the presence of water after a rate-limiting initial step, without the need for reaction progress through fructose as the intermediate (Fig. 6).

\section{Selectivity during reaction progress}

In the reaction of carbohydrates to HMF, stochiometric dehydration and the formation of various organic acid side products affects the water content and the $\mathrm{pH}$ of the reaction medium. Mechanistic changes during reaction progress are thus to be expected. The experiments of Fig. 6 were used to extract kinetics and selectivity of $\mathrm{Cr}^{\prime \prime \prime}$-catalysed glucose conversion during reaction progress. Changes in the rate and in the
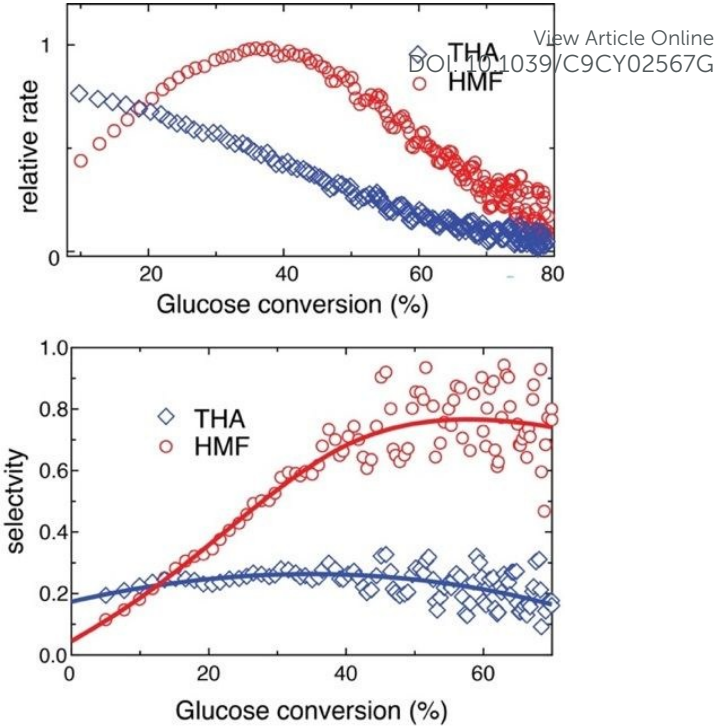

Fig. 7. Rate and selectivity of HMF and THA formation plotted against the reaction progress (glucose conversion). Data are shown for the reaction with $30 \%$ ( $/ \mathrm{v}$ )
added water in the reaction mixture (raw data of Fig. 6 bottom) and lines are a guide to the eye.

selectivity of glucose conversion to THA and HMF are depicted in Fig. 7 as functions of substrate conversion. These plots indicate that the selectivity of THA formation remains largely constant during the reaction, albeit at continuously reduced reaction rates. In contrast, selectivity for the formation of HMF increases from a low initial level, as glucose initially is converted to intermediates (fructose and compound $\mathbf{1}$ ), and possibly as the consequence of effects from Brønsted acidic products such as THA. The selectivity for HMF thus remains high at conditions, where reaction rates have declined to approximately $10 \%$ (Fig. 7). Selectivities determined from real-time qNMR data are consistent with literature data describing $~ 80 \%$ selectivity to $\mathrm{HMF}$ in the $\mathrm{CrCl}_{3} / \mathrm{DMSO}$ system in the presence of water. ${ }^{18}$ In addition, the selectivity for THA formation remains slightly below $20 \%$. These analyses paint a picture of glucose conversion to HMF and THA side products, with a very minor contribution of other side products in the presence of water.

\section{Water-enabled THA formation with other catalysts and solvents}

The Cr'll-catalysed conversion of glucose to HMF has attracted interest for use in various solvent systems, including pure water and pure DMSO. ${ }^{11,18}$ Figure 8 uses ${ }^{1} \mathrm{H}^{-13} \mathrm{C}$ HSQC spectra to show the gradual compositional changes of post-reaction material formed from glucose by $\mathrm{Cr}^{\prime \prime \prime}$ catalysis in solvent systems containing $0-100 \%$ water in DMSO. The water-enabled THA formation increases in selectivity relative to HMF with increasing water content. Rehydration and degradation of HMF contributes to the shift in selectivity and becomes significant under the chosen reaction conditions above $60 \%$ water, as signified by the increased formation of formic acid under these conditions. Figure 8 indicates that THA formation can constitute a rather major pathway in $\mathrm{Cr}^{\text {III-}}$-catalysed glucose conversion. 


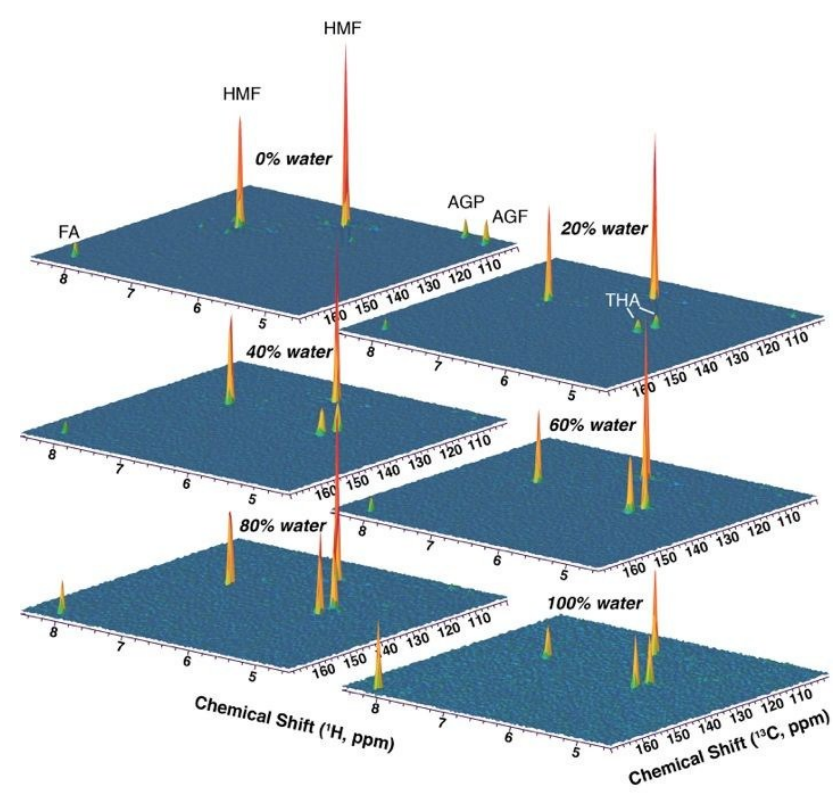

Fig. 8. ${ }^{1} \mathrm{H}-{ }^{13} \mathrm{C} \mathrm{HSOC}$ spectral region showing changing selectivity in the range of $\mathrm{O}$ $100 \%$ water in DMSO. AGF and AGP are anhydrosugars (Figure S6). FA denotes formic acid. Reaction conditions: $30 \mathrm{mg}$ glucose, $2.5 \mathrm{mg}$ CrCl3.6 H2O at $100{ }^{\circ} \mathrm{C}$ in $550 \mu \mathrm{l} d 6-D M S O$ or D2O with the indicated composition (v/v).

Water-enabled THA formation was likewise observed when employing In'II or Al"I catalysts, or when using other organic solvent systems such as $\gamma$-valerolactone or 1,4-dioxane (Fig. S11-S13). Overall, the pathway to THA thus emerges as a rather widely relevant competitive pathway in the formation of HMF.

\section{Conclusions}

The malleability and solvent control in the popular $\mathrm{Cr}^{\text {III- }}$ catalysed conversion of glucose to HMF in DMSO was followed using quantitative in situ NMR. For commercialization, the formation of value-added side products in this reaction may become similarly important as changes to the HMF yield itself in the presence of added or liberated water. The prospective polyester building block THA is the dominant side product in the presence of water, while a mixture of inert compounds constitutes the side products in the absence of water. Isotope distributions in HMF permit quantifying the initial influx of

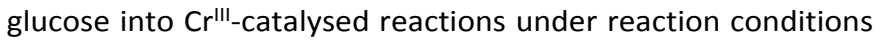
to HMF. Initial hydride shift reactions are only little affected by the presence of water, while 1,2 C-shift is noticeably reduced in water. In contrast, fructose dehydration is strongly hindered in the presence of water, consistent with theoretical considerations. ${ }^{30}$ Various solvent systems and catalysts indicate that the pathway to THA is a widely relevant competitive pathway in the formation of HMF.

\section{Conflicts of interest}

There are no conflicts to declare.

\section{Acknowledgements}

This work was supported by Innovation Fund Denmmark (Gase

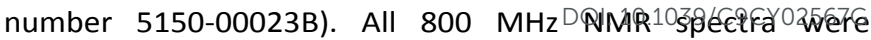
recorded on the spectrometer of the NMR center DTU supported by the Villum Foundation.

\section{References}

1 C. Figueres, H. J. Schellnhuber, G. Whiteman, J. Rockström, A. Hobley and S. Rahmstorf, Nature, 2017, 546, 593-595.

2 H. Nguyen, V. Nikolakis and D. G. Vlachos, ACS Catal., 2016, 6, 1497-1504.

3 B. F. M. Kuster, Starch - Stärke, 1990, 42, 314-321.

4 R.-J. van Putten, J. C. van der Waal, E. de Jong, C. B. Rasrendra, H. J. Heeres and J. G. de Vries, Chem. Rev., 2013, 113, 14991597.

5 F. H. Newth, in Adv. Carbohydr. Chem., eds. C. S. Hudso and S. M. Canto, Academic Press, 1951, vol. 6, pp. 83-106.

6 M. J. Antal, W. S. L. Mok and G. N. Richards, Carbohydr. Res., 1990, 199, 91-109.

7 C. Moreau, R. Durand, S. Razigade, J. Duhamet, P. Faugeras, P. Rivalier, P. Ros and G. Avignon, Appl. Catal., A, 1996, 145, 211224.

8 E. Taarning, I. Sádaba, P. R. Jensen and S. Meier, ChemSusChem, 2019, 12, 5086-5091.

9 H. Zhao, J. E. Holladay, H. Brown and Z. C. Zhang, Science, 2007, 316, 1597.

10 C. B. Rasrendra, J. N. M. Soetedjo, I. G. B. N. Makertihartha, S. Adisasmito and H. J. Heeres, Top. Catal., 2012, 55, 543-549.

11 V. Choudhary, S. H. Mushrif, C. Ho, A. Anderko, V. Nikolakis, N. S. Marinkovic, A. I. Frenkel, S. I. Sandler and D. G. Vlachos, J. Am. Chem. Soc., 2013, 135, 3997-4006.

12 S. H. Mushrif, J. J. Varghese and D. G. Vlachos, Phys. Chem. Chem. Phys., 2014, 16, 19564-19572.

13 P. R. Jensen, E. Taarning and S. Meier, ChemCatChem, 2019, 11, 5077-5084.

14 Y. Zhang, E. A. Pidko and E. J. M. Hensen, Chem. Eur. J., 2011, 17, 5281-5288.

15 R. S. Assary, P. C. Redfern, J. Greeley and L. A. Curtiss, J. Phys. Chem. B, 2011, 115, 4341-4349.

16 L. Yang, G. Tsilomelekis, S. Caratzoulas and D. G. Vlachos, ChemSusChem, 2015, 8, 1334-1341.

17 K. Yan, C. Jarvis, J. Gu and Y. Yan, Renew. Sustain. Energy Rev., 2015, 51, 986-997.

18 S. Jia, Z. Xu and Z. C. Zhang, Chem. Eng. J., 2014, 254, 333-339.

19 I. Tosi, S. G. Elliot, B. M. Jessen, A. Riisager, E. Taarning and S. Meier, Top. Catal., 2019, DOI: 10.1007/s11244-019-01144-7.

20 F. A. A. Mulder, L. Tenori and C. Luchinat, Angew. Chem., Int. Ed., 2019, 131, 15427-15430.

21 T. Szyperski, Eur. J. Bioch., 1995, 232, 433-448.

22 C. Yang, Q. Hua and K. Shimizu, Metab. Eng., 2002, 4, 202-216.

23 S. G. Elliot, E. Taarning, R. Madsen and S. Meier, ChemCatChem, 2018, 10, 1414-1419.

24 W. Deng, P. Wang, B. Wang, Y. Wang, L. Yan, Y. Li, Q. Zhang, Z. Cao and Y. Wang, Green Chem., 2018, 20, 735-744.

25 S. Meier, Catal. Comm., 2020, 135, 105894.

26 S. Meier, Anal. Bioanal. Chem., 2014, 406, 7763-7772.

27 Y. Román-Leshkov, J. N. Chheda and J. A. Dumesic, Science, 2006, 312, 1933.

28 K.-i. Shimizu, R. Uozumi and A. Satsuma, Catal. Commun., 2009, 10, 1849-1853.

29 A. S. Amarasekara, L. D. Williams and C. C. Ebede, Carbohydr. Res., 2008, 343, 3021-3024.

30 M. A. Mellmer, C. Sanpitakseree, B. Demir, P. Bai, K. Ma, M. Neurock and J. A. Dumesic, Nat. Catal., 2018, 1, 199-207.

31 H. Li and R. L. Smith, Nat. Catal., 2018, 1, 176-177.

32 H.-S. Chen, A. Wang, H. Sorek, J. D. Lewis, Y. Román-Leshkov and A. T. Bell, ChemistrySelect, 2016, 1, 4167-4172. 


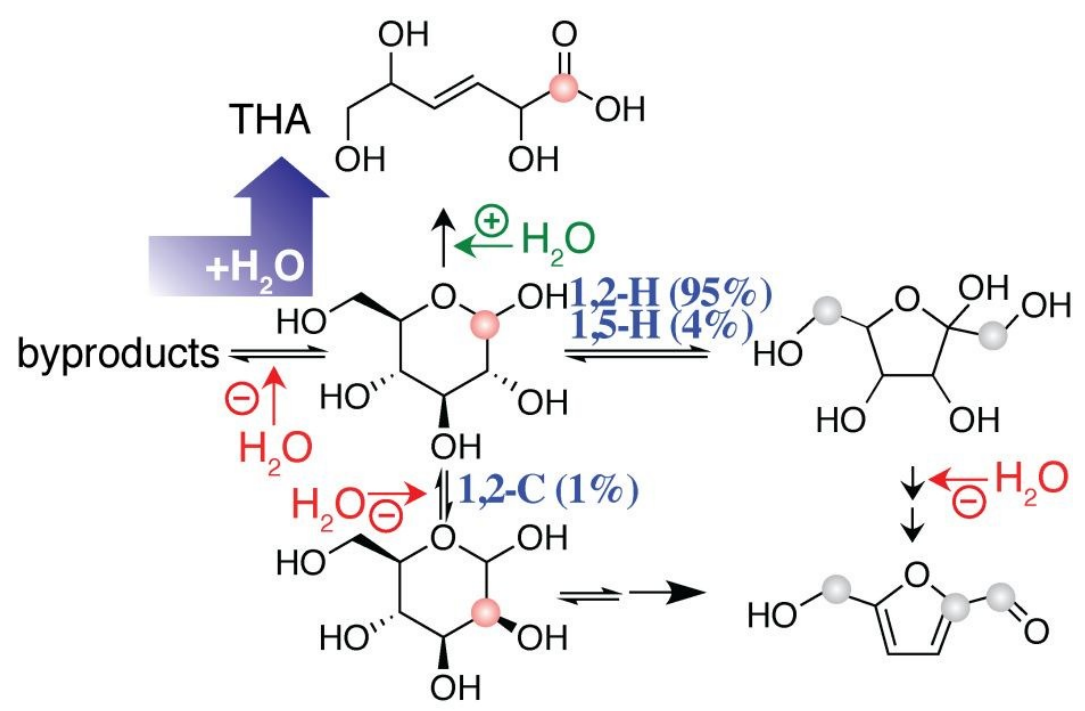

A water-enabled reaction to a polyester building block is found to widely occur in the conversion of glucose to HMF. 